\title{
The Categorisation of Tax Jurisdictions in Comparative Tax Law Research
}

\author{
Renate Buijze*
}

\begin{abstract}
The number of comparative tax law studies is substantial. The available literature on the methodology behind these tax comparisons, however, is rather limited and underdeveloped. This article aims to contribute to the theoretical background of tax comparisons by explicating methodological considerations in a comparative tax research on tax incentives for cross-border donations and relating it to the available methodological literature. Two aspects of tax law make comparative research in tax law a challenging endeavour: its complexity and fast-changing nature. To overcome these issues, this article proposes to divide jurisdictions into a limited number of categories. In this process the different legal levels are analysed systematically, resulting in categories of jurisdictions. Among the jurisdictions in one category, common characteristics are identified. This results in an abstract description of the category. I use the term 'ideal types' for these categories. The high level of abstraction in the use of ideal types allows for comparison of tax jurisdictions, without the risk that the comparison gets outdated. An additional advantage of working with ideal types is that the conclusions of the comparison can be applied to all jurisdictions that fit in the ideal type. This increases the generalisability of the conclusions of the comparative tax research.
\end{abstract}

Keywords: Classification of jurisdictions, international comparative tax law, tax law methodology

\section{Introduction}

When researching tax law it is interesting to see how different countries deal with one and the same issue. Approaches can be very similar, but can also vary largely. Comparing different jurisdictions gives an idea of alternative measures to an issue. Usually, a legal comparison can provide insights into the political, social and cultural climate in a country. Contrasting one's own jurisdiction with another also improves the understanding of one's own jurisdiction. For these and for other reasons, many tax law scholars have engaged in tax law comparisons.

\footnotetext{
PhD candidate at the Erasmus University Rotterdam. Email: buijze@law.eur.nl. This article was written as part of the research programme of the Erasmus School of Law on 'Fiscal Autonomy and its Boundaries'. The author would like to thank Prof. Dr. Sigrid Hemels and the two anonymous peer reviewers for their helpful comments.
}

Also in the field of my research interest - tax incentives for philanthropy in personal income tax - scholars have conducted country comparisons. ${ }^{1}$ One of the findings of the comparisons is that there is a high level of consensus regarding the encouragement of philanthropy through the tax system among high-income countries, as $87 \%$ of high-income countries provide a tax incentive for donations by individual benefactors in personal income tax acts. $^{2}$ Despite this high level of consensus in domestic situations, governments have far more diverging approaches when it comes to cross-border situations. Differences in approaches of governments towards the application of tax incentives to cross-border philanthropy emerge in the comparisons made by several tax law scholars. They analysed the impact of the developments in EU law on the application of tax incentives for crossborder donations. Furthermore, they compared the relevant tax provisions on the use of tax incentives for crossborder philanthropy of countries in and outside the EU. ${ }^{3}$ Each of them, for obvious reasons, focused on a limited number of countries. These studies demonstrate that there are countries that restrict tax incentives for charitable giving to the own country. Others allow for tax incentives in personal income tax on cross-border gifts. The conditions under which a tax incentive for a cross-border gift can be obtained, however, vary largely and the full range of requirements passes by, from stringent requirements to limited requirements.

1. For recent comparisons see, among others, S. Heidenbauer, 'Exclusiveness and Directness in Charity Law: A Comparison', 25 Steuer und Wirtschaft International 283 (2015); F. Vanistendael (ed.), Taxation of Charities (2015): and Nexus, McDermott Will \& Emery LLP, Charities Aid Foundation, Rules to Give by: A Global Philanthropy Legal Environment Index (2014).

2. Nexus, McDermott Will \& Emery LLP, Charities Aid Foundation, above n. 2. High income economies are those with a Gross National Income per capita of $\$ 12.736$ or more, World Bank, 'New Country Classifications by Income Level', available at: <http://data.worldbank.org/news/ new-country-classifications-2015> (last visited 17 July 2015).

3. See, among others, H. Jochum and A. Savvaidou, 'Deduction of Gifts and Contributions and Other Tax Incentives in the PIT and CIT for NonProfit Entities or Activities', in F. Vanistendael (ed.), Taxation of Charities (2015) 61; T. von Hippel, Cross-Border Philanthropy in Europe after Persche and Stauffer: From Landlock to Non-Discrimination? (2014); S. Heidenbauer, S.J.C. Hemels, B.W. Muehlmann, M. Stewart, O. Thömmes \& T. Tukić, 'Cross-Border Charitable Giving and Its Tax Limitations', 67 Bulletin for International Taxation 611 (2013); M. Stewart, 'Tax Deductibility of Cross-Border Giving: Australia Gives No Quarter', Melbourne Legal Studies Research Paper 605 (2012), S. Heidenbauer, Charity Crossing Borders, the Fundamental Freedoms' Influence on Charity and Donor Taxation in Europe (2011); and I.A. Koele, International Taxation of Philanthropy (2007). 
The example of tax incentives for cross-border philanthropy demonstrates that countries with a similar approach towards domestic situations can have divergent approaches to the same topic in cross-border situations. Comparison of these different approaches towards cross-border taxation, similarly to the comparison of domestic tax law, provides interesting insights. Conducting a comparative tax law research, however, can be challenging. In other legal areas one can rely on the available methodological literature when engaging in comparative research. The literature on comparative tax law, however, is rather sparse and fragmented. Comparative tax law studies either lacked a description of their methodological approaches or started from scratch and failed to engage with the comparative tax research conducted by others. ${ }^{4}$ By making the method that I used explicit and relating it to other methodological contributions, this article aims to contribute to the methodological understanding of comparative tax law, more specifically to the comparison of measures for cross-border taxation. Furthermore, the newly developed guidelines used during the classification of tax jurisdictions are put forward. This seems worthwhile since few scholars have made their methodology explicit. It is an invitation to others to make their methodology in comparative tax law explicit as well, in order to strengthen the field of comparative tax law.

The categorisation of tax jurisdictions took place in the light of a study I conducted on tax incentives in personal income tax for cross-border charitable gifts. ${ }^{5}$ Through the analysis of the relevant tax sources, I classified tax jurisdictions into ideal types that capture the spectrum of different approaches governments hold towards the application of tax incentives in cross-border situations. The ideal types vary from jurisdictions that support cross-border donations with a tax incentive, to governments that restrict tax incentives to domestic donations and models that represent the more moderate approaches between these extremes.

The article starts with a brief description of the status of comparative tax law within comparative law in Section 2. Section 3 identifies two main challenges that arise when comparing legislation on cross-border taxation, namely the complexity of tax systems and the rapid legislative change. The article continues with the description of the method I have used to compare countries' approaches towards tax incentives for cross-border philanthropy in Section 4. Special attention is paid to the classification of tax jurisdictions. Section 5 reflects on the use of ideal types in comparative tax law. In the last section I make some concluding remarks. Although the central aim of this article is to advance the methodology of comparative tax law, the discussion may be helpful for the study of cross-border legislation in other legal fields as well.

4. O.Y. Marian, 'The Discursive Failure in Comparative Tax Law', 58 The American Journal of Comparative Law 415 (2010).

5. R. Buijze, Charitable Fundraising for the Arts in the Era of Globalization: International Tax Barriers for Arts Organizations, forthcoming $\mathrm{PhD}$ thesis, Erasmus University Rotterdam.

\section{Comparative Law and Comparative Tax Law}

\subsection{Comparative Law and Comparative Tax Law}

It may indeed be that the mere interpretation of positive rules of law in the way traditionally practised by lawyers does not deserve to be called a science at all, whether intellectual or social. Perhaps legal studies only become truly scientific when they rise above the actual rules of any national system, as happens in legal philosophy, legal history, the sociology of law, and comparative law. ${ }^{6}$

This provocative statement by Zweigert and Kötz stimulates the reflection on traditional legal research. It shows that the discipline of law can benefit from approaches that go beyond the study of the national system. At the same time, it depicts that comparative law gains value when it goes beyond the study of foreign law and does not run ashore at the descriptive comparative law of country reports. Instead, these informative descriptions constitute the starting point for a critical comparative reflection on the phenomenon studied.

Comparative law is one method to go beyond the study of national legal systems. It has the potential to obtain a more profound understanding of law that is less directed to national legal systems and more targeted to overarching approaches and/or deeper underlying principles. Comparative research allows scholars to identify general, universal applicable legal principles. It allows them to understand, organise and structure law. And it allows the discovery of model solutions for preventing or resolving conflicts. ${ }^{7}$ Comparative law, however, is not an aim in itself. Instead, it is a method that provides a structure to find an answer to a research question. ${ }^{8}$

The discipline of comparative law came into being around the turn of the previous century. The first conference on comparative law was held in 1900 in Paris. ${ }^{9}$ Since then, many scholars have written on the methodology of comparing jurisdictions, although they do not perceive comparative law as a full-grown methodology. ${ }^{10}$ By comparative tax law, I refer to the methods used in comparative law applied to the field of tax law. Some scholars argue that comparative tax law is not just a

6. K. Zweigert and H. Kötz, An Introduction to Comparative Law (1998), at 4 .

7. H.P. Glenn, 'The Aims of Comparative Law', in J.M. Smits (ed.), Elgar Encyclopedia of Comparative Law (2012) 65 and Zweigert and Kötz, above n. 6 , at 4,15

8. Glenn, above n. 7, at 65 and W. Devroe, Rechtsvergelijking in een Context van Europeanisering en Globalisering (2010), at 37, 38.

9. V. Heutger and E. Schrage, 'Legal History and Comparative Law', in J.M. Smits (ed.), Elgar Encyclopedia of Comparative Law (2012) 505, at 512.

10. Zweigert and Kötz, above n. 6, at 33 . 
methodology, but a substantive body of knowledge. ${ }^{11}$ I agree with their line of reasoning that the methodology used is mainly a technique derived from comparative law and can lead to new knowledge in itself. In this article, however, I would like to focus on the former: the methodological contribution the approach and techniques of comparative tax law make to the discipline of tax law. Therefore, I address comparative tax law as a methodology in this article.

Comparative tax law has developed somewhat in isolation of comparative law in general, for two reasons. First of all, the emphasis in traditional comparative law used to be on private law. Key works on comparative law, until recently, did not address legal comparisons in tax law, although they paid attention to other fields of law, such as contract law, tort law, family law and, more recently, areas in public law, such as administrative law and constitutional law. ${ }^{12}$ Second, owing to the high level of specialisation in tax law, tax specialists are usually the ones conducting comparative tax law instead of legal comparatists.

Comparisons are of great importance, though, in the field of tax law. Civil servants and practitioners who negotiate or apply tax treaties, for instance, need to have knowledge of one or more foreign jurisdictions in order to understand and apply the treaty. The increasing integration of supranational legislation with domestic tax law demands more knowledge of comparative tax law as well. In the EU, this is caused by the harmonisation of indirect taxes and the harmonisation on sub-areas of direct taxes. Furthermore, there is no other area in law for which the Court of Justice of the European Union (CJEU) has produced as much jurisprudence as for tax law, which requires amendments of national tax legislation.

The importance of comparative tax law for practice has put its mark on comparative tax law in academia. Most of the research in this field is pragmatic. Moreover, it is often descriptive in nature, describing the legal practice on a specific topic in a selection of jurisdictions. In cases where it is more analytic, the emphasis in the research is often on one single country. When considering the importance of comparative tax law for practice ${ }^{13}$ and the large number of tax scholars who engage in comparisons, ${ }^{14}$ it is surprising that relatively little has been written on the methodology of comparative tax law. Tax law is notoriously fast changing and complex, which makes the comparison of tax law a challenging endeavour. Therefore, methodological guidance is important for tax law comparatists.

11. R.S. Avi-Yonah, N. Sartori, \& O. Marion, Global Perspectives on Income Taxation Law (2011), at 1-2 chapter 2 and Marian, above n. 4, at 421 .

12. See, amongst others, Zweigert and Kötz, above n. 6; P.G. Monetary (ed.), Methods of Comparative Law (2012) and M. Adams and J. Bomhoff, Practice and Theory in Comparative Law (2012).

13. V. Thuronyi, 'Tax Law', in J.M. Smits (ed.), Elgar Encyclopedia of Comparative Law (2012) 867.

14. Ibid

\subsection{Methodology in Comparative Tax Law}

The methodology of comparative law is rather young and develops by trial and error. ${ }^{15}$ This definitely holds for comparative tax law. Tax law scholars for a long time omitted to contribute to methodology shaping. Not that there was a total absence of methodological literature, but the majority of tax law comparatists started from scratch in developing their method and omitted to take the work of others into account. Furthermore, they omitted to explicate how they got to the used methodology after earlier attempts. This resulted in largely varying, sometimes even conflicting, but underdeveloped methodology for comparative tax law and a lack of comparative tax discourse, ${ }^{16}$ and made it difficult to learn from one another. A conversion is going on, however. Marian, for example, related existing comparative tax law research to the methodological framework of comparative tax law. ${ }^{17} \mathrm{By}$ doing so he contributed to the methodology, or discourse as he calls it, of comparative tax law. I believe this is an important step, since comparative legal methods have a lot to offer to the discipline of tax law.

Comparative legal methods have the potential to contribute to the field of tax law in several ways. Through comparison with other tax jurisdictions, comparative tax law allows for a better understanding of the own system. ${ }^{18}$ It stimulates scholars to think creatively about legal problems and broadens their perception of the technical available measures to achieve a certain policy goal. ${ }^{19}$ When designing new legislation, comparative tax law can provide inspiration and it can identify best practices and threats to the success of potential new legislation. Furthermore, it can be used to add structure to the field of tax law, which can be used in further research. Besides, comparative tax law can help gain an understanding of the legal context. ${ }^{20}$ Finally, it is relevant for practice. It gives insight into the underlying differences between jurisdictions, which is necessary, for example, to manage cross-border transactions.

\subsection{Different Kinds of Comparative Tax Law}

The degree and type of comparative research conducted in tax law differ largely. There is comparative tax law that provides analytical comparisons, where comparisons of national systems are made within a specific assessment framework. This type of comparative tax law is normative and/or evaluative. An example of methodological explanation of comparative tax law that uses

15. Zweigert and Kötz, above n. 6 at 33 and W. Twining, Globalization and Comparative Law (2000) at 191-92.

16. Marian, above n. 4 , at 417 .

17. Ibid

18. W.B. Barker, 'Expanding the Study of Comparative Tax Law to Promote Democratic Policy: The Example of the Move to Capital Gains Taxation in Post-Apartheid South Africa', 109 Penn State Law Review 703, at 708 (2004-2005) and H.J. Ault and M.A. Glendon, 'The Importance of Comparative Law in Legal Education: United States Goals and Methods of Legal Comparisons', 27 Journal of Legal Education 599, at 601 (1975).

19. H.J. Ault and B.J. Arnold, Comparative Income Taxation: A Structural Analysis (2004) and Ault and Glendon, above n. 18.

20. V. Thuronyi, Comparative Tax Law (2003). 
an assessment framework to make an analytical comparison is the work of Barker. ${ }^{21}$ He made a critical analysis of the South African capital gains tax in comparison with that in the United Kingdom and the United States, in order to assess how the tax system can help solve economic inequality in an emerging democracy. Barker is of the opinion that comparative tax law should go beyond mere description and should be critical. He states: 'Comparative analysis needs to confront the assumptions underlying tax law including its effect, efficiency, fairness, and acceptance by the people. This means it must go beyond descriptive focus on the "is" and evaluate the "is" in the terms of the "ought to be." 22 Another interesting example that strives for the "ought to be" through a tax law comparison is the study by Infanti. ${ }^{23}$ Infanti conducted research on the tax treatment of cross-border contributions to charities, just as I did. He, however, uses the comparative tax law method to demonstrate how -according to his presumption - simplification of the domestic tax regime can be achieved through tax coordination at the international level.

Moreover, there is research that makes comparisons based not on a normative assessment framework, but on the characteristics of the tax jurisdiction. This type of comparison aims not to evaluate, but to structure tax jurisdictions. The structure in itself can be seen as a result and helps gain insight into tax jurisdictions outside the own jurisdiction. What is more important, perhaps, is that the created structure can assist in answering more explanatory, predictive and defining research questions. Ault and Arnold, in their canonical work, created a structure along which they could discuss the income taxation of nine industrialised countries. ${ }^{24}$ Unfortunately, these authors pay little attention to the theory underlying their comparison. The research in which I categorise high-income countries according to their approach towards the application of tax incentives for cross-border donations is a similar type of comparison. By explicating the used methodology, my work is aimed at providing insight into this type of tax law comparison.

Finally, a large part of the comparative tax law literature is descriptive in nature. Tax law scholars have written highly informative descriptions on the legislation in a specific field of tax law in their jurisdictions. Examples are country reports, which are bundled into edited volumes. These publications are very helpful for practitioners and academics that search for an introduction to a foreign tax jurisdiction. Tax legislation is complex, and therefore country reports are a very welcome starting point from which to get a basic understanding of a foreign jurisdiction. The purpose of these overviews is mainly informative, which is exactly why they are helpful to tax comparatists. On the other hand, some schol-

21. Barker, above n. 18

22. Ibid., at 708.

23. A.C. Infanti, 'Spontaneous Tax Coordination: On Adopting a Comparative Approach to Reforming the U.S. International Tax Regime', 35 Vanderbilt Journal of Transnational Law 1105 (2002).

24. Ault and Arnold, above n. 19. ars might question whether they belong to comparative tax law in the narrow sense, since it misses a normative approach or does not produce a body of knowledge. ${ }^{25}$ When a summary of the national reports is added to the edited volume, trends might be identified. ${ }^{26}$ This, again, is perceived as comparative tax law by the majority of scholars.

\section{Challenges in Comparative Tax Research on Cross- Border Taxation: A Complex and Fast-Moving Target}

Comparative tax law research is complicated by three aspects of tax law: rapid legislative change, the complexity of tax systems and the heterogeneity of local tax concepts. $^{27}$ These challenges present in comparative tax research also appear, and are perhaps even more pronounced, when comparing topics in the field of crossborder taxation. The heterogeneity of local concepts, however, appears in many fields of comparative law and is discussed extensively by others. ${ }^{28}$ Therefore, I will only mention that the translation of foreign tax concepts requires great caution and that one should be aware of the different meanings of seemingly similar concepts. ${ }^{29}$ The other two factors, however, do require some explanation.

Comparative research on tax legislation is complicated by continuous political pressure and changing government standpoints. This results in ongoing changes in tax legislation over time. For instance, the requirements for Algemeen Nut Beogende Instellingen (Public Benefit Pursuing Entities) in the Netherlands have changed five times between 2008 and 2014. ${ }^{30}$ When dealing with cross-border issues, one has to take into account (changes in) legislation in two countries. Political changes and decisions at the international level also add to the rapid pace of changes in tax law. The case law of the CJEU, for example, is a source of amendments to national law. This makes tax law, especially cross-border taxation, a fast-moving target that is difficult to grasp and poses the risk of comparative tax research getting outdated fast.

25. C. Garbarino, 'An Evolutionary Approach to Comparative Taxation: Methods and Agenda for Research', 57 The American Journal of Comparative Law 667, at 679 (2009).

26. Marian, above n. 4 , at $455-56$.

27. Garbarino, above n. 25, at 686-88.

28. See, among others, L. Hantrais, International Comparative Research, Theory, Methods and Practice (2009) at 72-94; G.R. de Groot and C.J.P. van Laer, 'The Dubious Quality of Legal Dictionaries', 34 International Journal of Legal Information 65 (2006).

29. See, among others, Garbarino, above n. 25, at 686-88; M.A. Livingston, 'Law, Culture, and Anthropology: On the Hopes and Limits of Comparative Tax', 18 Canadian Journal of Law \& Jurisprudence 119 (2005).

30. S.J.C. Hemels and W. van Vliet, 'Anbi: regeling of ontregeling?' 17 Vakblad Fondsenwerving 27 (2015). 
Another challenge in comparative tax research is to deal with the complex nature of tax law, especially in crossborder situations. The complexity of tax law stems from its distinctive tax vocabulary. Furthermore, the high degree of refinement in the tax provisions, which might be laid down in a large volume of varying legal sources, adds to the complex structure of tax law. ${ }^{31}$ This complexity causes a high level of specialisation among scholars and practitioners. In several OECD countries, for example, specialisation in the field of tax law is the norm and generalists are exceptional. ${ }^{32}$ The impact of nation$\mathrm{al}$, international and/or supranational legislation on each other further adds to the degree of complexity of tax law, especially on cross-border tax issues. It provokes a 'vertical comparison', which is a comparison that compares legal systems at different legal levels. ${ }^{33} \mathrm{~A}$ comparison that checks whether a tax system of an EU Member State is in line with the four fundamental freedoms as stipulated in the Treaty on the Functioning of the European Union (TFEU) would be an example. ${ }^{34}$ So unlike the traditional horizontal comparison, which is a comparison occurring among systems belonging to the same level, ${ }^{35}$ comparisons of (cross-border) taxation provoke both horizontal and vertical comparisons. Furthermore, in some cases an unequal comparison might arise because some countries have larger sovereign powers than others.

The foregoing factors make it difficult to get a hold on one's own tax jurisdiction, let alone fully understanding multiple tax jurisdictions. The boundaries between legal orders, expressed in horizontal and vertical relations, get blurred owing to the integration of legal orders. ${ }^{36}$ At the same time, the large impact that legislation at the international and/or supranational level has on national legislation and vice versa increases the demand for comparative tax law. As Thuronyi nicely puts it: "EU integration fuels some of the demand for comparative tax law knowledge." 37

To overcome the challenges that the fast-changing and complex nature of international tax law pose to comparative tax law, I propose a method for comparative tax law that categorises tax jurisdictions into ideal types. The benefits of this method are that it enables a systematic analysis of tax jurisdictions in their international legal context and that it provides durable outcomes. Besides, the ideal types enable generalisation of the conclusions to other countries. In the next section I explain how the tax jurisdictions are categorised into ideal types, so that other researchers can reflect on this method when engaging in similar comparative tax law research.

\footnotetext{
31. Livingston, above n. 29, at 120; Thuronyi, above n. 20, at 17-20.

32. Thuronyi, above n. 13, at 863

33. A. Momirov and A. Naudé Fourie, 'Vertical Comparative Law Methods: Tools for Conceptualising the International Rule of Law', 2 Erasmus Law Review 291 (2009)

34. Treaty on the Functioning of the European Union (TFEU) and EU Treaty (as amended through 2007).

35. Momirov and Naudé Fourie, above n. 33

36. Devroe, above n. 8, at 37-56.

37. Thuronyi, above n. 13 , at 862
}

\section{The Comparison of Approaches to Tax Incentives for Cross-Border Philanthropy}

\subsection{Conducting Comparative Legal Research} Zweigert and Kötz distinguish the following five steps in conducting comparative research: (a) definition of the research topic and research question; (b) selection and interpretation of sources; (c) selection of countries; (d) comparison of the country reports and (e) building of a system. ${ }^{38}$ Other comparative law scholars like Kamba and Örücü provide similar guidelines for conducting comparative law, albeit with slightly different emphasis. ${ }^{39}$ Infanti, who also conducted research on the tax treatment of cross-border contributions to charities, adopted the guidelines proposed by Kamba. ${ }^{40}$ Although we study the same topic, the different aims of our comparative tax law research, logically, direct me to a different approach. Whereas Infanti's work aims to develop a method that achieves simplification of the domestic tax regime through tax coordination at the international level, my research aims to explore the different approaches towards the application of tax incentives for cross-border donations. It is the steps identified by Zweigert and Kötz that I largely drew on in the comparison of approaches to tax incentives for cross-border philanthropy.

The comparative tax law research in which I explore the different approaches towards the application of tax incentives on cross-border donations is part of a larger research project that evaluates the solutions that allow private donors to benefit from the domestic tax incentive for donations on cross-border donations. This specific topic determines the scope of the comparison: a specific facility in personal income tax, and thus a micro comparison. ${ }^{41}$

The starting point of the actual research was the exploration of the literature on cross-border charitable giving. This exploration led to the main research question: 'What are the dominant approaches towards the application of tax incentives in personal income tax for crossborder individual giving?' In line with Zweigert and Kötz advice, I kept away from terms related to a specific jurisdiction. Instead, I selected a concept that grasps the functionality of the rules I wanted to study. I chose the term 'tax incentives' instead of 'tax credit', 'tax deduction' and the like, because the latter refer to measures used in specific jurisdictions, whereas the former covers

38. Zweigert and Kötz, above n. 6, at 32-47.

39. W.J. Kamba, 'Comparative Law: A Theoretical Framework', 23 International and Comparative Law Quarterly 485 (1974); A.E. Örücü, 'Methodology of Comparative Law', in J.M. Smits (ed.), Elgar Encyclopedia of Comparative Law (2012) 560.

40. Infanti, above n. 23.

41. Marian, above n. 4 , at 449-51. 
the entire category of measures that support charitable giving through the income tax system.

For the exploratory research, I consulted scientific articles by tax law scholars from a diversity of countries. This provided a good idea of the primary sources to consult for the actual research. Although I had initially considered the comparison of domestic tax legislation and a separate discussion of international and supranational legislation, I soon learned that this was insufficient. Domestic tax legislation, bilateral tax treaties and supranational agreements all had to be taken into account in the comparison. During the data collection I thus searched for information relevant to tax incentives for charitable giving in all these three sources. The advantage of studying a tax benefit is that these benefits are generally well described in the written law. This is in contrast to other types of provisions, where unwritten rules might be present that can be difficult to track down for non-native scholars. The great consensus among high-income countries in regard to the application of tax incentives for charitable giving helped me a great deal in finding the relevant provisions in the legislation.

In addition to the written law, important case law was studied. This was initially limited to case law of courts at the international level such as the CJEU. Later, when it showed that in one jurisdiction written law was not in line with the CJEU case law and there was uncertainty about the law in practice, clarification was found in the case law of the highest tax.

To gain insight into the application of domestic tax law, in the first instance the original documents were consulted. But when language barriers forced consultation of secondary sources, I turned to respectable secondary sources, and explicitly noted in the reports wherever applicable that they were based on secondary sources. ${ }^{42}$ Even though translations of the original documents were available, caution was required since certain concepts are difficult to translate. Besides, similar concepts can have a different meaning, owing to the influence of the socio-cultural context in a country.

The exploratory research included a broad variety of jurisdictions. For the actual research, the initial selection of jurisdictions had to be limited. Zweigert and Kötz propose two approaches for the selection of jurisdictions: (a) selecting jurisdictions from different legal families or (b) selecting on the basis of the function of the topic in the research. ${ }^{43}$ I chose the latter, as I wanted to ensure that a variety of approaches towards the application of tax incentives for cross-border philanthropy were included in the research. In the exploratory

42. Respectable secondary sources were used in case language barriers prevented consultation of original legislation, such as the Tax Research Platform of IBFD (<http://online.ibfd.org>) country reports gathered by the European Foundation Centre and Transnational Giving Europe (<www.efc.be/programmes_services/resources/Pages/Legal-and-fiscalcountry-profiles.aspx> and <www.transnationalgiving.eu/en/countryprofiles/ $>$ ), the Council on Foundations (<www.cof.org $>$ ) and the publication following the 2012 Conference of European Tax Law Professors (F. Vanistendael (ed.), Taxation of Charities (2015)).

43. Zweigert and Kötz, above n. 4, at 40-42. research I had identified the main varieties of tax incentives for philanthropy. The exploratory research also provided insight into the relevant legal orders that influence the approaches governments hold towards the application of tax incentives for cross-border philanthropy. These factors were guiding in the selection of jurisdictions, in order to ensure that the existing diversity of jurisdictions would be represented in the selection. On the basis of this purposeful selection I chose the following jurisdictions: Australia, Barbados, Belgium, France, Germany, Hungary, Japan, Netherlands, Spain, Sweden, the United Kingdom and the United States. This selection of jurisdictions includes examples of the entire spectrum of approaches towards the application of tax incentives on cross-border philanthropy. Additional countries would closely resemble one of the jurisdictions included in the selection and would therefore not foresee new insights. In other words, I had reached the point of decreasing marginal returns. ${ }^{44}$ Since the research focuses on a very specific provision, it was feasible to study this rather large selection of jurisdictions. This would, for obvious reasons, be impossible if the research topic encompassed a more general rule.

Despite using a purposeful selection, unintendedly the selected jurisdictions cover most of the tax law families as identified by Thuronyi. ${ }^{45}$ Barbados, Australia and the United Kingdom represent the Commonwealth family; the United States represents the American family; the French family is covered by France; Hungary belongs to the transition and post-conflict family; the Netherlands, Belgium, Germany and Sweden represent the Northern European family; Spain belongs to the Southern European family; and Japan represents the Japanese/Korean family. The families identified by Thuronyi that are not covered by this selection are the Latin American family and the miscellaneous family. None of the countries in the miscellaneous family are high-income countries and therefore fall outside my comparison. Among the Latin American family, Uruguay, Argentina, Chile and Venezuela qualify as high-income countries, and the latter three also seem to have a tax incentive for private giving in place. ${ }^{46}$ The existing literature on cross-border charitable giving did not give rise to including these countries in the selection, although for the future it might be interesting to have a closer look at (one of) these countries.

For each of the twelve selected jurisdictions I made a brief country report. In order to enlarge the reliability of my interpretation of the sources consulted I crosschecked my findings with academic articles by native scholars of the relevant jurisdictions, in so far as these were available. To make the country reports comparable, I had to use an approach to all jurisdictions that would allow me to eliminate the elements that are peculiar to a jurisdiction, but stand in the way of comparison. These elements are, for example, tax concepts spe-

\footnotetext{
44. Ibid., at 41.

45. Thuronyi, above n. 20, at 23-44

46. Nexus, McDermott, Will \& Emery, Charities Aid Foundation, above n. 2.
} 
cific to one jurisdiction and cultural interpretations. To eliminate these, I followed the functional approach. This commonly used approach in comparative law, which is also adopted in comparative tax law, assumes that the basic function of legislation in each country can be compared. It starts from a specific problem and then examines which mechanisms are used in the jurisdictions studied to resolve it. The mechanisms for each function can then be grouped on the basis of the function. ${ }^{47}$ My method differs from the functional approach in later steps, where the functional approach searches for similarities in tax legislation and is used as a tool "for reform leading to harmonization or even unification of tax lams" ${ }^{48}$ Instead, my aim is not to reform tax law, but to map the different legislative models. Here I find my approach close to that of Thuronyi, who sees comparative tax law as an instrument that provides a structure for reference in tax law. ${ }^{49}$ Besides, I did not focus solely on the similarities, but also took into account the differences between jurisdictions.

While constructing the country reports, similarities and differences between countries started to become clear. I could see patterns crystallising, and that is how I got to the division of jurisdictions into ideal types. However, before describing the categorisation of jurisdictions in the next section, a word of caution is necessary. Although categorisation is helpful as a system, the discussion of tax law in terms of ideal types does come with some drawbacks. As in every legal comparison, there are the language barriers to overcome. ${ }^{50}$ Furthermore, jurisdictions are heavily interrelated with the societal and cultural background of the country. ${ }^{51}$ In addition, one should look not only at the written law, but also at the law in action. ${ }^{52}$ Therefore, getting a thorough understanding of a jurisdiction other than that in your home country can be difficult. One should be aware, when engaging in comparative tax law, that systems might seem the same but the institutional and cultural backgrounds might differ. ${ }^{53}$ This can be a threat to a successful comparison. With the help of work by native scholars and the support of generous reviewers and colleagues, however, it is possible to get a grip on a foreign legal system.

\subsection{Categorisation Regarding Tax Incentives for Cross-Border Gifts}

The relation between the different legal levels and the level of openness of a country towards the application of tax incentives for cross-border philanthropy showed to be the key to a system based on which the different approaches could be divided into ideal types. According to Zweigert and Kötz, this 'system building' is the last

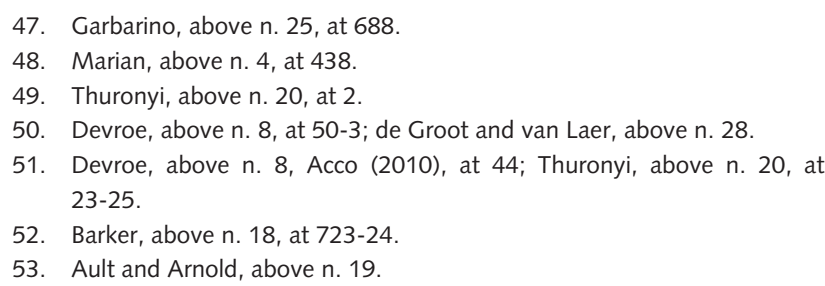

step in comparative research, ${ }^{54}$ as the division into ideal types enables a macro-perspective on a specific and detailed topic. Based on the type of tax incentive available, the availability of legal measures at different legal levels and the requirements imposed on qualifying donations, I built a system in which the jurisdictions can be ordered in a meaningful sequence. This requires some explanation. In the next paragraph I elaborate on the relevant factors.

At the national level countries choose a specific tax incentive scheme, such as a credit on taxes due, a deduction from taxable income or a percentage designation scheme. In principle, these tax incentives can all be applied in cross-border situations. Countries grant tax incentives in cross-border situations under certain conditions. They can allow for a tax incentive on direct cross-border donations or on cross-border donations through a local intermediary charity. The local intermediary charity is a qualifying charity in the country of the donor that receives the gift and then transfers it to a foreign charitable organisation. Since the transaction from the donor to the local intermediary charity is a donation to a domestic qualifying organisation, a tax incentive is granted on the gift. Obviously, a country that allows for direct cross-border donations has a more open approach than countries that only allow for tax incentives on indirect cross-border donations.

Through the design of the tax incentive and the requirements imposed on a qualifying donation, governments can nuance the application of the tax incentive. The requirements can vary from administrative requirements, to requirements on the location of the designated organisation, to definitions on what activities qualify as charitable and requirements over the control over the receiving charity. The requirements imposed on qualifying donations are a strong tool to limit or loosen the applicability of tax incentives to cross-border donations, for countries that allow for tax incentives on cross-border donations based on national legislation, but also for countries that allow this based on international and/or supranational legislation. The more requirements and the stricter the requirements imposed on a qualifying donation, the more difficult it is to make a cross-border donation with the benefit of a tax incentive, and thus the more closed a jurisdiction is on this issue.

At the international level, countries can engage in bilateral tax treaties in which they recognise each other's charities and mutually apply their tax incentives to cross-border donations. The more bilateral tax treaties a country has that include a provision on charitable contributions, the more open the approach of a country is.

Also at the supranational legal level, countries can engage in agreements on this topic. In the European Union (EU), for example, the CJEU in the Persche case ruled that based on the free movement of capital, donations to charitable organisations that meet the charity requirements of the donor's state should be treated equally, regardless of whether it concerns a donation

54. Zweigert and Kötz, above n. 6, at 44-46. 
within an EU Member State or crossing borders between two EU Member States or an EU Member State and a country that is part of the European Economic Area. ${ }^{55} \mathrm{EU}$ Member States that want to limit the scope of this judgment can alter their national legislation in such a way that the requirements on qualifying donations become restrictive, as long as they stay within the limits of the Persche case.

The factors that influence the applicability of a tax incentive for cross-border donations, described in this section, are measures at different legal levels that are guiding in the comparison and ranking of tax jurisdictions according to their openness towards the application of tax incentives for cross-border donations. The road map in the next section summarises this in a more structured manner. Applying this road map results in four ideal types: (1) closed jurisdictions; (2) restrictive jurisdictions; (3) relatively open jurisdictions and (4) open jurisdictions. These ideal types inform us how open a jurisdiction is towards the application of a tax incentive on a charitable gift. Countries without a tax incentive in place at the domestic level fall outside the comparison.

Although the jurisdictions could have been divided into a different number of categories, four ideal types showed to be the right number, as these four ideal types summarise the spectrum of different approaches governments hold towards the application of tax incentives for cross-border philanthropy. While developing the system, I also made an attempt to divide the jurisdictions into three and five ideal types. Three ideal types did not allow inclusion of all the factors discussed above. More than four ideal types forced a divide on less meaningful components and would have made it more complex to deal with the categories.

\subsection{Categorisation of Jurisdictions: A Road Map $^{56}$}

The categorisation of the jurisdictions into ideal types was done as systematically as possible, in order to increase the internal validity. The following steps were taken:

1. Does the domestic tax legislation allow for tax incentives on direct cross-border donations? If yes, $>$ ideal type (4) open jurisdiction.

2. Does the domestic tax legislation allow for tax incentives on indirect cross-border donations (through a local intermediary charity) and/or does the country have international agreements, such as tax treaties and/or supranational agreements, that allow for tax incentives on cross-border donations

a. with at least ten countries? And

b. of which the facts and circumstances make it practically possible to obtain a tax benefit on a cross-

55. CJEU, 14 October 2008, Case C-318/07, Hein Persche v. Finanzamt Lüdenscheid.

56. In this section I cite my own work to illustrate the application of the method I propose in this article. See R. Buijze, 'Approaches Towards the Application of Tax Incentives for Cross-Border Philanthropy', 44 (1) Intertax (2016) border situation? If yes $>$ ideal type (3) relatively open jurisdictions.

3. Does the country have international agreements, but with less than ten countries, and/or are the facts and circumstances such that it is impossible to obtain a tax benefit for a cross-border donation in practice? If yes $>$ ideal type (2) restrictive jurisdiction.

4. None of the above? If yes $>$ ideal type (1) closed jurisdictions.

\subsection{Four Approaches towards the Application of} Tax Incentives for Cross-Border Gifts

Based on the road map above, the different jurisdictions were divided into four categories that summarise the spectrum of the different approaches governments hold towards the application of tax incentives for cross-border donations. A last step to take was to identify the common qualities of each category, in order to define the four ideal types. To identify these characteristics, I went back again to the country reports, but this time to search for similarities within the jurisdictions that belong to one category. I described the ideal types as follows. ${ }^{57}$

Countries that stimulate charitable gifts through tax incentives in the domestic situation but not in a crossborder situation are considered closed tax jurisdictions. In their tax system, these countries provide a benefit to benefactors of charity organisations, for example, through a tax credit or deduction from taxable income. Closed jurisdictions, however, do not have domestic legislation that allows for a tax benefit for cross-border donations, nor do they have bilateral or supranational agreements with other countries on tax incentives for cross-border donations. Examples of these countries are Australia and Japan.

At present, countries that use a tax designation scheme (also known as percentage schemes) typically also belong to this ideal type. The majority of jurisdictions that apply a tax designation scheme to support philanthropy limit tax incentives on philanthropy to donations in the own country, although it is technically possible to allow for cross-border donations in a tax designation scheme. The tax designation schemes are designed such that taxpayers in their tax declaration can allocate a percentage of their taxes due to a charity that is included in a list of eligible charities. In this list often solely domestic charities are included. Since the gift to the charity is made through the tax declaration, it is difficult for the taxpayer to have a say in the spending of the contribution. This limits the possibility to use the recipient charity as an intermediary charity. Currently, most of the jurisdictions that use a tax designation scheme have a closed approach towards the application of tax incentives for cross-border charitable giving. This, however, is not inherent to tax designation schemes, but to how a specific jurisdiction adopts this tax designation scheme.

57. In the following paragraphs I cite my own research to illustrate the outcome of the method I propose. In the article I cite from, however, this text belongs to the core content of the research. See Buijze, above n. 56. 
Hungary is one of the countries in the EU that uses a tax designation scheme and that I consider a closed tax jurisdiction.

In restrictive jurisdictions a tax incentive can be obtained for cross-border donations, based on bilateral tax treaties or supranational agreements. However, the scope of these agreements is limited, allowing for tax incentives on cross-border donations with no more than ten countries. Owing to the limited scope of the agreements these jurisdictions are considered restrictive.

Furthermore, countries with more agreements, but where it is practically cumbersome to receive a tax benefit, are included in this ideal type. I add this criterion to avoid that those countries where it is legally possible but practically close to impossible to receive a tax benefit on a cross-border donation, to end up in the relatively open category. For example, EU Member States need to allow for tax incentives in cross-border situations. However, in practice it proves to be extremely difficult in some Member States to obtain this benefit, since EU law based on the TFEU and CJEU case law is simply not applied. These jurisdictions try to restrict the tax incentives to the domestic situation as much as possible and are therefore effectively in the category 'restrictive jurisdictions'. A local intermediary organisation might provide a solution in this type of jurisdictions to obtain a tax incentive for cross-border donations. Examples of these jurisdictions are the United Kingdom, France and Spain.

A more moderate category are the relatively open tax jurisdictions, which do allow for tax incentives on crossborder donations, but mainly based on tax treaties and supranational agreements. The scope of these agreements is rather broad and covers more than ten countries. Furthermore, the facts and circumstances make it practically feasible to obtain a tax benefit on a cross-border donation. Besides, in these countries it is also possible to obtain a tax incentive for a cross-border donation through local intermediary charities. Belgium, Germany and the United States are examples of this ideal type.

Open tax jurisdictions are those countries that allow for tax incentives on cross-border donations, based on domestic tax regulations. They do so in cross-border situations with multiple countries. Regardless of whether donations are made domestically or internationally, tax privileges can be obtained. Thus, there is no discrimination between donations made to domestic charities and those made to foreign charities. In both cases the donor receives the same tax privilege. The Netherlands, Barbados and Sweden fit within this ideal type.

\section{Reflections on the Categorisation into Ideal Types}

Many scholars propose that only a limited number of jurisdictions can be compared, because of the available resources, accessibility to sources and time limitations. I subscribe to these claims. However, this greatly limits the generalisability of the findings of the research, since the legal comparison will only hold for the discussed jurisdictions. Under the most favourable conditions it can be cross-checked whether the conclusions drawn from the legal comparison can also apply to another jurisdiction. But this, of course, requires a full analysis of the additional jurisdiction. By limiting oneself to a small selection of countries, comparisons can get bogged down in studies that inform us on the current legal situation in the discussed jurisdictions and their differences and similarities. Although the informative value of these studies should not be underestimated, it does have limitations. Furthermore, a comparison of a small number of jurisdictions is not generalisable over time. As soon as legislation changes, the comparison is outdated, and thus the conclusions are largely obsolete.

To contribute to fundamental scientific knowledge, it is desirable to have more abstract findings, so that they can be applied to other jurisdictions. This is exactly what the categorisation I propose has to offer. Working with ideal types allows for conclusions at a higher level of abstraction. This stimulates conceptualisation and helps reveal relations within tax legislation. Findings can be generalised to other jurisdictions geographically, but also over time. Jurisdictions are not static, so if legislation is adjusted, it is sufficient to check whether the changes impact the categorisation of the jurisdiction. If necessary, the jurisdiction can be shifted to a different ideal type.

Although presented here in the light of cross-border taxation, the method might be of use to cross-border issues in other fields of law. The prerequisite is, though, that the approach can be grasped in an ordinal discrete variable, e.g. a qualitative measure that can be ordered in a meaningful sequence. Furthermore, this ranking of approaches has to be related to the different legal levels it is subject to. Another prerequisite to apply the method used here is that there is a certain degree of convergence among jurisdictions studied.

Distilling four ideal types that summarise the spectrum of approaches towards the application of tax incentives for cross-border donations, based on the analysis of twelve jurisdictions was possible because of the great convergence between different jurisdictions, despite the fact that each country's tax laws are unique. ${ }^{58}$ Several causes are conceivable for this great coherence. Jurisdictions can belong to the same legal family, which are groups of jurisdictions characterised by their style of legal thought. ${ }^{59}$ Another reason might be that governments adopt successful laws from other countries. This practice is known as legal transplants. ${ }^{60}$

In the field of cross-border charitable giving, countries might also look at each other for successful measures at different legal levels to restrict or open their jurisdiction

58. Thuronyi, above n. 20 , at $15-17$.
59. Barker, above n. 18 , at 711 .

60. Ibid., at 716 . 
towards the application of tax incentives for cross-border donations. This would explain why it was possible to clearly identify four different ideal types. This brings me to the similarities between the categorisation of tax jurisdictions I propose with that of the 'typological method' of legal comparisons.

The typological method is a variation of the functional method, which was briefly addressed in Section 4. In the functional method, law is studied in practice, according to its function. The typological method builds on this by searching for a solution to a specific problem in the different judicial systems around the world, the so-called wholesale approach. Solutions to the problem are distilled from jurisdictions, and from these specific solutions, type-solutions are identified. Type-solutions are model solutions under which the other solutions can be classified. The type-solutions are the base for a divide of jurisdictions in different categories of groups of solutions. These groups can intersect legal families. ${ }^{61}$ In the categorisation I propose, the type-solutions can be found in the different legal levels. Each different legal level provides a different type-solution that allows for the application of tax incentives on cross-border philanthropy. Based on these type-solutions, the different approaches towards the application of tax incentives are classified and indeed these groups do intersect legal families.

The congruence we see in the approaches of governments towards legal issues is also helpful for comparatists to assess the quality of the comparison. It helps to evaluate whether a broad enough scope was taken. If only few different approaches are found, one can wonder whether the researcher included enough jurisdictions. On the other hand, the researcher can be confident that his or her study is complete if the addition of jurisdictions does not lead to additional categories. ${ }^{62}$

Categorising jurisdictions into ideal types, however, is not suitable for every aim. In the discussion of tax jurisdictions in terms of ideal types, the peculiarities and nuances that every jurisdiction has are lost to a large extent. Therefore, the method proposed is not suitable when one aims at drawing conclusions for a specific jurisdiction. Detailed analysis of the jurisdiction concerned is necessary to draw conclusions for a specific jurisdiction. The aim of the ideal types is to achieve a certain level of abstraction and not to reach out towards specific jurisdictions. Although no conclusions can be drawn for one specific jurisdiction, a lot can be learned when using this approach. As Ault and Arnold write:

Doing meaningful comparative analysis is especially difficult in the tax area, where political pressure, chance and historical accident have all had an important influence on the development of the systems. However, with appropriate caveats and cautions, there is much to learn in the tax field from a comparative analysis of common problems. One need not believe in the existence of a Platonic Tax Form to find useful insights in the experience of others. ${ }^{63}$

\section{Concluding Remarks}

Comparative law methods can contribute to the field of tax law. It provides tools to gain a profound understanding of tax law, it uncovers universal applicable legal principles and helps to identify model solutions. For these and other reasons, tax law scholars have engaged in comparative tax law. Few of them, though, have made their methodology explicit, and among those who have explicated their method the majority failed to relate it to the methodology used by other tax law comparatists.

To contribute to the methodology of comparative tax law, this article elaborated on comparative research, specifically focusing on cross-border tax issues, the challenges involved and how to overcome these challenges. The two main challenges specific to comparative tax law on cross-border tax issues are the fast-changing nature of tax legislation and the complexity involved in crossborder tax issues because of the different legal levels involved.

To overcome these two issues in a study of the different approaches towards the application of tax incentives for cross-border donations, I developed a technique in which jurisdictions are categorised into ideal types. In essence, the categorisation takes place on the basis of measures available at the different legal levels to which the jurisdiction is subject and which resolve the crossborder tax issue. Through this method, categories are developed in which each country receives a ranking based on which it can be assigned to an ideal type.

By creating ideal types the model increases the comparability of jurisdictions regarding cross-border taxation. This results in a structured overview of the broad range of approaches towards international tax law. Once the ideal types are established, determining the position of one specific jurisdiction in the broad range of tax jurisdictions becomes more straightforward. This makes it easier to deal with changes in legislation. The method thus allows for easy expansion of the countries studied and is resistant to the dynamic nature of tax legislation. Besides, the use of ideal types allows for generalisation beyond the study of one specific jurisdiction. It enables a broader generalisation of findings.

The ideal types in themselves contain a body of knowledge. They provide an overview of different approaches towards a cross-border tax issue. However, they can also be used as the starting point for further research into more specific issues. One could, for example, analyse the legal measures a taxpayer can rely on in one of the ideal types and see which of the available measures solves a cross-border issue most effectively and efficiently. 